\title{
Upstream Market Foreclosure
}

J. Gabszewicz and Sk. Zanaj

Discussion Paper 2006-24

Département des Sciences Économiques

de l'Université catholique de Louvain 


\title{
Core Discussion Paper 2006/43 \\ Upstream market foreclosure
}

\author{
Jean J. Gabszewicz * \\ and \\ Skerdilajda Zanaj ${ }^{\dagger}$
}

February 24, 2006

\begin{abstract}
This paper investigates how an incumbent monopolist can weaken potential rivals or deter entry in the output market by manipulating the access of these rivals in the input market. We analyze two polar cases. In the first one, the input market is assumed to be competitive with the input being supplied inelastically. We show that this situation opens the door to entry deterrence. Then, we assume that the input is supplied by a single seller who chooses the input price. In this case, we show that entry deterrence can be reached only through merger with the seller of the input.

Keywords: entry deterrence; foreclosure, overinvestment; bilateral monopoly.

JEL Classification: D20, D43, L42.
\end{abstract}

${ }^{*}$ CORE, Université catholique de Louvain, Belgium

${ }^{\dagger}$ CORE, Université catholique de Louvain, Belgium and University of Siena, Italy. This work was supported by a Marie Curie Fellowship from the European Commission. We are grateful to Nathalie Sonnac and Paul Belleflamme for their stimulating comments. 


\section{Introduction}

The competitive effects of upstream market control have been extensively investigated under the assumption that this control is exercised through vertical merging activities. But alternative exclusionary practises are often observed in the upstream markets. Think of the strategy of some very wellknown italian soccer teams, like AC Milan, which in the early nineties, did not accept to sell some of their players they were not using to other teams simply in order to avoid competition. Think also of young scientific scholars trained in the best universities and hired by them while they are still completing their Ph.D's. Similarly, when a dominant undertaking in the diamond industry systematically preempts any newly discovered diamond mine in order to prevent other smaller competitors to benefit from this new source of input supply. Another famous example with the same flavour is the Standard Oil which accepted to pay substantial higher fares to the railways companies to prevent these companies to carry rivals' oil (see Granitz and Klein (1996)).

A recent discussion paper of the DG Competition on the application of art. 82 of the Treaty provides a good description of such exclusionary practises. In this document, one among other origins of barriers to entry in a market is described as: "Privileged access to supply: the allegedly dominant undertaking may be vertically integrated or may have established sufficient control or influence over the supply of inputs that expansion or entry by rival firms may be difficult or costly" (emphasis added). The first alternative envisaged in this citation - vertical integration - has been extensively investigated theoretically in Salinger (1988), Ordover, Saloner and Salop (1990), Rey and Tirole (2003) among many others, and empirically in more than 500 papers (see Joskow (2005) for a survey). An example of these empirical investigations is Martin, Norman and Snyder (2001) who, through experimental economics techniques, find evidence that vertical integration increases the ability of the upstream firm to bottle up output and increase prices, consistently with Ordover, Salop and Saloner. In the present paper, we model and analyse the exclusionary conduct of an incumbent from the viewpoint of the second alternative evoked in the DG Competition discussion paper. In particular we evaluate the strategies used by a monopolist in the downstream market in order to prevent an entrant to have access to an input which is essential in the production process, thereby deterring entry in the market for the final good.

Due to the recent uprise of pro-competitive product market regulation through antitrust authorities, competition in these markets has dramatically increased in several industries (see OECD Outlooks, 1999). In order to pre- 
vent this competition to be too harmful to them, the firms concerned by this regulation have tried to substitute to more traditional entry deterring strategies used in the downstream market (like predatory pricing or horizontal merging), strategies directed to the upstream markets corresponding to inputs used in the production process of the final goods. Among these strategies, we can list vertical integration, raising rivals' costs or delocalisation of productive activities into countries with lower input costs. The payoffs resulting from the use of such strategies depend not only on the competitive conditions under which the upstream input markets operate before their use, but as well as on the technical relations existing between inputs and output. It is easier for a price-maker in the downstream market to leverage its power into a competitive input market than when it faces market power in the upstream market. As regarding technology, when the production of the final good can be realised through several substitutable inputs, it is more difficult for the downstream price-maker to succeed in controlling the output market supply since it would require the control of several upstream markets. Consequently, a full-fledged analysis of such strategies can hardly be performed without making explicit assumptions about input market structure and technology. In this paper, we make such explicit assumptions. From the viewpoint of the input market structure, we analyse two polar cases, namely, a competitive market and a bilateral one. As far as technology is concerned, we assume a single input and linear production function for the output. These simplifying assumptions allow us to compute unambiguously the payoffs of the strategies opened to the incumbent monopolist. We also assume an inelastic supply in the input market.

First, we derive the monopoly equilibrium in the output market assuming that the input is bought at equilibrium price in the competitive input market. Since the total amount of input available is exchanged at equilibrium, it corresponds to the blockaded entry solution: no entry in the final market can occur because no more input is available for potential rivals.

Then we investigate the resistance of the blockaded entry to shocks on the supply of the scarce input, like the discovery of new natural sources, or entry of a new upstream firm. The threat of entry in the output market originates from these shocks. When entry is fully or partially accommodated, the incumbent and the entrant play a Cournot game in the output market. We show that both entry deterrence and full accommodation can be observed at the subgame perfect equilibrium, while partial accommodation cannot be part of a subgame perfect equilibrium of the game.

Then we examine the same question assuming a bilateral monopoly in the input market. In this polar case, the cost of the downstream monopolist is no longer defined at the input price corresponding to a competitive input 
market. In fact, this cost now depends on the exchange rate selected by the upstream monopolist. As a consequence, there is no strategy available to the downstream firm to deter entry when an external shock arises in total input supply : the only way to escape competition in the final good market consists in a cooperative agreement, like a merger or long term contract with the input seller. We show that in our model the necessary condition to make this agreement successful is satisfied.

Our work is methodologically related to the seminal paper by Dixit (1980) on the role of investment to deter entry. The basic point made in his paper is the incentive of an incumbent firm to undertake investments in order to control the ex-post Cournot equilibrium which could result from the entry of a competitor in the output market. We use a similar two-stage game methodology to model how the incumbent controls the access in the output market to a potential competitor. However, while Dixit does not take into account the existence of an input market, we introduce it explicitely in our analysis of entry deterrence. Furthermore, the rationale in our model is not to precommit to agressive strategies, as in Dixit, but to deny the access to the input market making infinite the input costs of the potential rivals.

Another trend of the literature to which our approach can be naturally related deals with the possibility for the incumbent to raise rivals' costs and thereby induce exit of fringe competitors from the final market. Differently from this literature, we investigate the best reply of the incumbent to the threat of entry in an oligopolistic setup. More precisely, we deal with a monopolist firm in the output market that intends to leverage its market power to the input market, either by preempting input in a competitive environment, or through a non-cooperative interaction with the upstream firm. Also, as in the case of Dixit, the input market is not formally introduced in the model analysed by Salop and Scheffman (1983, 1987), and it is not explained how the incumbent proceeds in this market in order to raise the cost of the the competitors.

The paper is organized as follows. In section 2 we set out the monopoly solution; in section 3, we introduce the threat of entry following a shock on the input supply when the input market is assumed competitve. Section 4 is devoted to the same question in a bilateral monopoly context. Finally, some possible extensions of the model are presented in our concluding comments. 


\section{Competition in the input market}

\subsection{Monopoly}

Consider an incumbent who is a monopolist in the output market, but behaves as a price taker in the input market $^{1}$; for simplicity we assume that production takes place through the use of a single input via the linear technology

$$
q=\alpha z,
$$

where $q$ stands for output, $z$ for input and $\alpha$ is assumed to be smaller or equal to one ${ }^{2}$. The supply of input is assumed totally inelastic to price but constrained to be smaller or equal to a fixed stock $S$ available in the market. The firm faces a linear demand for the output $a-b q$. The monopolist knows the initial level of the input $S$ available. The profit $\pi_{M}(z, p)$ under pure monopoly is given by

$$
\pi_{M}(z, p)=(a-b \alpha z) \alpha z-p z
$$

where $p$ stands for the price of the scarce input. Hence, we get from profit maximization the demand $z^{d}(p)$ for the fixed input, which is also the quantity of output produced divided by $\alpha$ :

$$
z^{d}(p)=\frac{\alpha a-p}{2 b \alpha^{2}} .
$$

The corresponding profit $\pi_{M}(p)$ of the monopolist writes as

$$
\pi_{M}(p)=\frac{1}{4} \frac{(a \alpha-p)^{2}}{b \alpha^{2}} .
$$

Since input supply is equal to $S$ we get from the equilibrium input market condition the corresponding equilibrium price $p_{M}^{*}$ and, consequently, the values of the production and the profit of the incumbent. From the market equilibrium condition we get

$$
p_{M}^{*}=a \alpha-2 b \alpha^{2} S .
$$

The price $p_{M}^{*}$ is nonnegative if the inequality $S \leq \frac{1}{2} \frac{a}{b \alpha}$ holds. To this price corresponds the output quantity $q_{M}^{*} \underset{\text { def }}{=} \alpha S$. It follows that the demand in the

\footnotetext{
${ }^{1}$ We assume that the monopolist behaves like a price taker in the input market, in fact, it is possible to introduce an "external" demand for the same input, coming from many other small firms in other industries: Think for example of a firm that uses wheat only to produce biofuel while many firms use wheat to produce bread.

2 The reason for introducing this assumption is explained in footnote 3 .
} 
input market at this price fully absorbs the existing stock of input, leading to a profit $\pi_{M}\left(p_{M}^{*}\right)=b \alpha^{2} S^{2}$ for the monopolist ${ }^{3}$.

Thus, if the input stock is limited and if the market equilibrium condition in the input market is satisfied, entry in the output market is automatically blocked, guaranteeing the persistence of monopoly, unless an external shock takes place. This situation corresponds to what Bain christened as blockaded entry. Notice that this conclusion holds when the monopolist's technology to produce the final good does not allow the use of an alternative input.

\subsection{Entry}

Now assume that the incumbent has to face a shock on input supply, leading to an increase $\Delta S$ in its availability. Consequently the total amount of input in the downstream market is now $S+\Delta S=\phi(\Delta S)$. This shock could follow from the entry of another seller in the upstream market or from a discovery of a new source of a raw (or primary) factor. Then, the monopoly position of the incumbent is threatened in the output market since a potential entrant can now buy this increase in input, and produce the same output. We assume that the potential entrant has the same technology as the incumbent firm. Two opportunities are opened to the monopolist in order to avoid competition in the output market (see Fig 1). In the first, he completely forecloses the input market buying the total amount of the input increase $\Delta S$ (deterred entry). In the second, he accommodates entry, in which case he can either partially ration the potential entrant buying some restricted part of $\Delta S$ (partial accommodation) or allow him to freely enter the market (full accommodation). In the two last subcases, we assume that the incumbent and the entrant play a Cournot game in the output market and behave as price takers in the input market while the price in the latter adjusts at equilibrium. Under partial accommodation, they play a constrained duopoly in the output market since the entrant cannot produce at free Cournot, being rationed in the input market.

In the following, we study the subgame perfect equilibrium of the game described above in which the incumbent chooses between the strategies "deter" or "accommodate" in the first stage and, if he has chosen the strategy "accommodate", the entrant and the incumbent select in the second stage the quantities purchased in the input market. These quantities in turn un-

\footnotetext{
${ }^{3}$ The above analysis is only valid when $\alpha \leq 1$ for otherwise the quantity produced in the output market would generate a demand in the input market which could not be met, given the available stock. In order to consider the case when $\alpha>1$, it would be necessary to reconsider the way we have determined the level of output in the final market, because the optimal solution would then be constrained by input availability in the upstream market.
} 


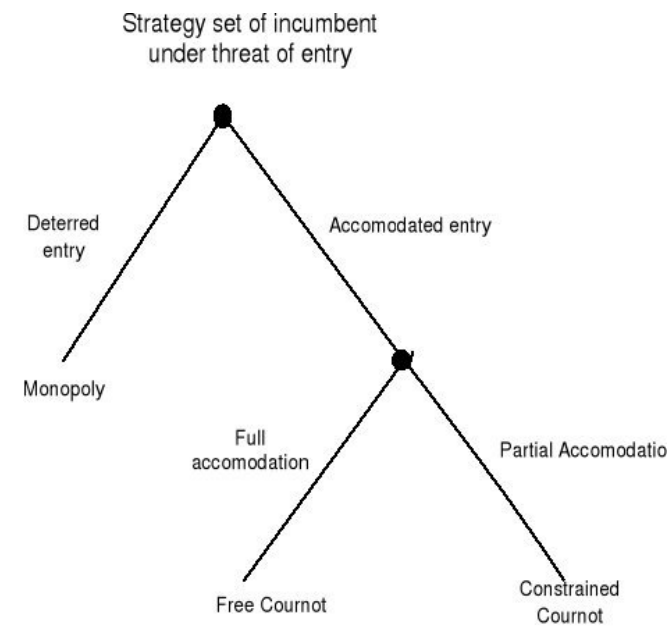

Figure 1: The Game

ambiguously determine the corresponding output levels in the downstream market.

\subsubsection{Deterred entry}

Under this alternative, the incumbent buys the whole input supply $\phi(\Delta S)$ available in the market. We assume that this purchase is done at the previous price level, i.e. at the monopoly price $p_{M}^{*}{ }^{4}$. Accordingly, this entails an additional cost equal of $p_{M}^{*} \Delta S$, leading to a new total cost $\left(a-2 b q_{M}^{*}\right) \alpha \phi(\Delta S)$. Notice however that, in spite of the existence of this increase in input, the firm will go on producing the quantity $q_{M}^{*}$, which is the optimal one at the running monopoly price. This additional cost is sustained only in order to deter entry: the incumbent overinvests with the only aim to foreclose the downstream market to new entrants. The profit $\pi_{M}^{\prime}$ at deterred entry obtains as

$$
\pi_{M}^{\prime}=b\left(q_{M}^{*}\right)^{2}-\left(a-2 b q_{M}^{*}\right) \alpha \Delta S .
$$

\subsubsection{Full accommodation}

If entry is fully accommodated, the incumbent plays a Cournot game with the entrant in the output market. Given the demand function in this market,

\footnotetext{
4 This assumption means that the input price does not adjust infinitely fast to its new equilibrium value. Otherwise, it would mean again blockaded entry, since at this new equilibrium price, no input is left available to a potential entrant.
} 
the quantity produced by each firm is given by

$$
q_{1}=q_{2}=\frac{1}{3 b \alpha}(a \alpha-p),
$$

with a resulting profit $\pi_{c}(p)$ for the incumbent

$$
\pi_{c}(p)=\frac{1}{9} \frac{(a \alpha-p)^{2}}{b \alpha^{2}} .
$$

The corresponding price $p_{c}^{*}$ obtains as the solution of the equation

$$
\frac{2}{3} \frac{1}{b \alpha^{2}}(a \alpha-p)=\phi(\Delta S)
$$

namely,

$$
p_{c}^{*}=a \alpha-\frac{3}{2} b \alpha^{2} \phi(\Delta S) .
$$

Before figuring out the profit of Cournot competitors, we should state the conditions over the stock $S$ and the shock $\Delta S$, in order for $p_{c}^{*}$ to be nonnegative, namely $(\phi(\Delta S)=) S+\Delta S \leq \frac{2}{3} \frac{a}{b \alpha}$. Recall that from the monopoly equilibrium we found that the initial stock should also satisfy the condition $S \leq \frac{1}{2} \frac{a}{b \alpha}$. Hence, combining both conditions we obtain the admissible set of $S$ and $\Delta S$.

Under these conditions, substituting the price $p_{c}^{*}$ in the profit function of the incumbent, we obtain

$$
\pi_{c}\left(p_{c}^{*}\right)=\frac{1}{4} b \alpha^{2} \phi^{2}(\Delta S)
$$

Using the equality $\alpha S=q_{M}^{*}$ and equations (1) and (2), the difference between fully accommodated and deterred entry profits for the incumbent obtains as

$$
\frac{1}{4} b \alpha^{2} \phi^{2}(\Delta S)-b\left(q_{M}^{*}\right)^{2}+\left(a-2 b q_{M}^{*}\right) \alpha \Delta S .
$$

We can replace $q_{M}^{*}$ by $\alpha(\phi-\Delta S)$, so as to get the condition under which entry is fully accommodated as a function of the input supply $\phi(\Delta S)$ and of the shock on the input market, namely

$$
\phi^{2}(\Delta S)<\frac{4}{3}(\Delta S)\left(\frac{a}{b \alpha}+\Delta S\right)
$$

Figure 2 represents the inequality (4) in the $\{\Delta S, \phi(\Delta S)\}$-orthant, as well as the admissible set $\left\{\Delta S, S: \Delta S \leq \frac{1}{2} \frac{a}{b \alpha} \wedge S+\Delta S \leq \frac{2}{3} \frac{a}{b \alpha}\right\}$, in which the output price is nonnegative ${ }^{5}$.

\footnotetext{
${ }^{5}$ Figure 2 obtains under the following parametric values $a=b=\alpha=1$ and ( $S=$ $q_{M}^{*}=\frac{1}{4}$, for which the admissible set of shocks is $\left\{\Delta S: 0 \leq \Delta S \leq \frac{1}{2}\right\}$.
} 


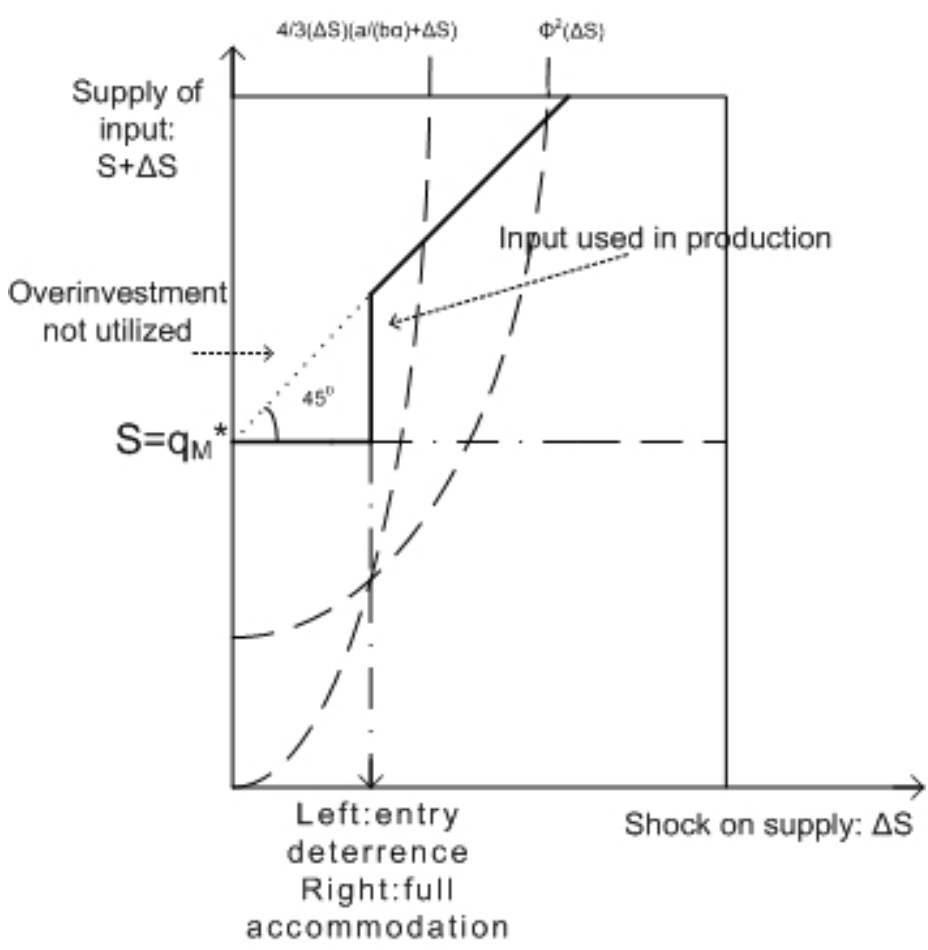

Figure 2: Full Accommodation and Entry Deterrence

Given the quantity corresponding to the blockaded entry, $q_{M}^{*}$, the intersection of the RHS and LHS parabola in (4) defines the threshold value, $\widetilde{\Delta S}$, of the shock that induces the incumbent firm to change her strategy from entry deterrence to accommodation. As long as the availability of the scarce input does not change for more than $\widetilde{\Delta S}$, as a result of the shock, the incumbent will overinvest in non utilized capacity as in Dixit $(1980)^{6}$. The bold curve represents the effective amount of input used in production represented: If the shock induces full accommodation the entire amount of input $S+\Delta S$ is going to be injected in the production of output.

The feasibility of the strategy to deter entry through upstream foreclosure is sensitive to output demand and technology parameters, respectively $a, b$ and $\alpha$. The higher the slope of the demand and the efficiency of the incumbent to produce the good $q$, the lower the RHS in condition (4), and, accordingly, the smaller the size of the shock leading the monopolist to deter entry.

Another way to interpret condition (4) consists in expressing it in terms of the difference between the cost of fully deterring entry and the discrepancy

\footnotetext{
${ }^{6}$ Given the technology, the investment in input can be seen as an investment in capacity.
} 
between the profits obtained by the monopolist when evaluated at two different values of the stock, namely $S$ and $S+\Delta S$. Let $\pi_{M}^{S+\Delta S}$ be the profit that the monopolist would obtain if the initial stock would be $S+\Delta S$ in place of $S$ and $C=p_{M}^{*} \Delta S$ the cost to deter entry at equilibrium, then condition (4) can be rewritten as ${ }^{7}$

$$
C \geq \pi_{M}^{S}-\frac{1}{4} \pi_{M}^{S+\Delta S}
$$

Of course, this interpretation is only valid when the price of the essential input is determined in a competitive market.

\subsubsection{Partial accommodation}

As we saw earlier, the incumbent can also buy some fraction of the increase $\Delta S$ in input supply in order to reduce the amount available to the entrant. We denote by $Z, S<Z<S+\Delta S$, the total quantity of input purchased by the incumbent. Since, by assumption, the entrant is constrained to buy a quantity of input smaller than the one used at the free entry equilibrium, the Cournot equilibrium in the output market is itself constrained for the entrant. The maximal amount of input the entrant can buy is thus equal to $S+\Delta S-Z$. The resulting supply of the entrant at the constrained Cournot equilibrium where the incumbent supplies $\alpha Z$ is the value of her best reply $\frac{\alpha a-b \alpha^{2}(S+\Delta S-Z)-p_{c}}{2 b \alpha^{2}}$. The resulting input price $p_{c}^{\circ}$ must satisfy the equilibrium condition, namely,

$$
\frac{1}{2}\left(\frac{a \alpha-b \alpha^{2}(S+\Delta S-Z)-p_{c}}{b \alpha^{2}}\right)+(S+\Delta S-Z)=S+\Delta S
$$

or

$$
p_{c}^{\circ}=a \alpha-b \alpha^{2}(S+\Delta S+Z)
$$

Given $Z$, the profit of the incumbent at the constrained Cournot equilibrium now writes as

$$
(a-b \alpha(S+\Delta S)) \alpha Z-\left(a \alpha-b \alpha^{2}(S+\Delta S+Z)\right) Z=\alpha^{2} b Z^{2} .
$$

It follows that the profit at the constrained Cournot is monotonically increasing in $Z$; accordingly it reaches its maximal value at $Z=S+\Delta S$. Consequently, partial accommodation cannot be in the equilibrium path of the game. Thus, when the accommodation strategy has been chosen by the incumbent in the first stage, only full accommodation can be observed in the second stage. The corresponding input levels bought by the incumbent and

\footnotetext{
${ }^{7}$ See appendix 1
} 
the entrant in the upstream market are $\frac{1}{2}(S+\Delta S)$ for each of them, leading to the unconstrained Cournot equilibrium in the downstream market. The following proposition summarizes our findings.

Proposition 1 In the first stage, the incumbent selects the strategy "deter" or "accommodate" according to ${ }^{8}$

$$
\phi^{2}(\Delta S) \gtrless \frac{4}{3}(\Delta S)\left(\frac{a}{b \alpha}+\Delta S\right) .
$$

When the incumbent has selected "accommodate" in the first stage, the incumbent and the entrant share total input $S+\Delta S$ at the second stage equilibrium, which leads to the free Cournot equilibrium in the output market.

The polar case to the one we have just analyzed consists of assuming that the input market is controlled by a single seller. Hence, the price and the quantity of input exchanged are determined in a bilateral monopoly. This is what we analyze in the next section.

\section{Bilateral monopoly}

In the framework we consider now there are two agents operating in the input market, the downstream and the upstream monopolist who supplies the input inelastically. The revenue function of the downstream monopolist - from now on the buyer - originates from the demand function of the final output and the price selected by the upstream monopolist. As for the revenue of the upstream monopolist firm - from now on the seller -, it is equal to the price the seller chooses times the quantity of input selected at that price by the buyer. In this situation, the seller is totally free to decide the share of the stock $S$ she wants to sell to the buyer. Consequently, the buyer in the input market cannot do better than accept the price set by the seller.

Under these assumptions, it is easy to derive the optimal price to be selected by the seller and accordingly the quantity exchanged in the market. Given $p$ the input quantity demanded by the buyer obtains from profit maximization in the output market, namely

$$
z_{M}(p)=\frac{\alpha a-p}{2 b \alpha^{2}}
$$

\footnotetext{
${ }^{8}$ When the condition is satisfied as an equality, the incumbent deters entry since he buys the entire amount of input in the upstream market.
} 
Accordingly, the profit of the seller, expressed as a function of $p$, writes as

$$
\left(\frac{\alpha a-p}{2 b \alpha^{2}}\right) p
$$

The optimal $\widetilde{p}$ is then given by

$$
\widetilde{p}_{M}=\max \left\{(a-2 b \alpha S) \alpha ; \frac{\alpha a}{2}\right\}
$$

The maximum obtains at $\widetilde{p}_{M}=\frac{\alpha a}{2}$ whenever $\frac{a}{4 b \alpha} \leq S$, while it obtains at $\widetilde{p}_{M}=(a-2 b \alpha S) \alpha$ whenever the reverse inequality holds ${ }^{9}$. Thus, a priori, two cases can arise in the input market: either the quantity exchanged, $\widetilde{z}=\frac{a}{4 b \alpha}$ is strictly smaller than $S$ or exactly equal to $S$. In order to make the following entry analysis symmetric with the analysis when the input market is competitive, we exclude this possibility by assuming from the outset that $\frac{a}{4 b \alpha} \geq S$. Hence, unless an external shock increases the level of input at the level $S+\Delta S$ no entry can occur. Consequently we pursue our investigation by assuming that only a shock in the input supply can lead to entry.

\subsection{Entry}

Since the incumbent firm cannot induce the upstream monopolist from selling to the entrant part of the excess input created by the shock, there is no longer any first mover advantage for the incumbent: deterring entry by manipulating the input market can no longer be practised. Accordingly, when a free Cournot can obtain in the downstream market, total demand in the input market is given by

$$
z_{c}(p)=\frac{2}{3 b \alpha^{2}}(a \alpha-p),
$$

and the profit of the upstream monopolist then writes as

$$
\frac{2}{3 b \alpha^{2}}(a \alpha-p) p .
$$

\footnotetext{
${ }^{9}$ In the first case, the corresponding quantity exchanged in the input writes as

$$
\widetilde{z}=\frac{a}{4 b \alpha},
$$

while in the output market the equilibrium price is $\frac{3 a}{4}$ and quantity is $\frac{a}{4 b}$. Notice that, using the inequalities $\alpha \leq 1$ and $\frac{a}{4 b \alpha} \leq S$, it is straightforward to show that the price of the output under bilateral monopoly exceeds the price when the input market is competitive. This reflects the market power of the seller in the upstream market.
} 
Profit maximization yields

$$
\widetilde{p}_{c}=\frac{\alpha a}{2},
$$

with corresponding total quantity of input $\widetilde{z}_{c}=\frac{a}{3 b \alpha}$. Hence,

Proposition 2 The downstream monopolist cannot prevent entry by manipulating the input market; the ensuing structure of the final market, namely, constrained or free Cournot, depends on the condition

$$
\frac{a}{3 b \alpha} \lessgtr S+\Delta S \text {. }
$$

When the stock exchanged is such that the downstream firms play a free Cournot, that is, when $\frac{a}{3 b \alpha} \leq S+\Delta S$, non utilized capacity can be observed at equilibrium.

The only remaining possibility for avoiding competition in the downstream market consists in reaching a cooperative agreement with the owner of the input resource. This agreement would take the form either of a merger or of a long term contract ${ }^{10}$ between the upstream and downstream monopolies. A necessary condition for the feasibility of this agreement is that there exists a possibility of sharing between the merger entities a joint profit, which exceeds the sum of the profits they could realise while staying out of the cooperative agreement. It is easy to check that this condition is indeed satisfied by direct comparison of the profits obtained in each of these alternatives (see appendix 2). As for the explicit solution to the bargaining problem raised by this situation, it cannot obtain without further restrictions on the bargaining process itself. Summarizing the above comments we get

Proposition 3 In order to prevent entry in the downstream market, there exists a production level in this market at which the corresponding profit of the merger entity exceeds the sum of the profits realised by the firms when entry is allowed in the downstream market.

\section{Conclusion}

We have studied how an incumbent monopolist can weaken potential rivals or deter entry in the output market by manipulating the access in the market for an essential input. Our analysis is based on a number of simplifying assumptions, like the use of the same linear technolology by the incumbent and

\footnotetext{
${ }^{10}$ See Aghion and Bolton (1987).
} 
the entrant or the presence of only one productive factor which is indispensable to production of the output. Natural extensions would be to explore the implications of alternative assumptions like an entrant using a more efficient technology or a production function including more than a single input. But the purpose of this paper was not to exhaust the possible details underlying the analysis of this problem, but simply to draw the attention of some scholars on this less known practise of upstream market foreclosure.

\section{References}

[1] Aghion, P. and Bolton, P.: "Contracts as a Barrier to entry", The American Economic Review, 1987, Vol.77, 388-401.

[2] Dixit, A.: "The Role of Investment in Entry-Deterrence", The Economic Journal, 1980, Vol.90, 95-106.

[3] DG Competition discussion paper on the application of Article 82 of the Treaty to exclusionary abuses, http://europa.eu.int/comm/competition/antitrust/others/discpaper2005

[4] Granitz, E. and Klein, B, :"'Monopolization by Raising Rivals' Costs: The Standard Oil Case"', The Journal of Law and Economics, 1996, Vol.39, 1-47.

[5] Joskow, P.L.: "Vertical Integration", American Bar Association Antitrust Section's "Issues in Competition Law and Policy" project, 2005.

[6] Martin, S., H.-T. Norman, and C. Snyder, "Vertical Foreclosure in Experimental Markets," RAND Journal of Economics, Vol. 32, 2001, 46649.

[7] OECD Economic Outlook, No.66, December 1999.

[8] Ordover, J. and Saloner, G. and Salop, S.: "Equilibrium Vertical Foreclosure", The American Economic Review, 1990, Vol.80, 127-142.

[9] Rey, P. and Tirole, J.: "A Primer on Foreclosure", 2003, in M.Armstrong and R. Porter (eds.), Handbook of Industrial Organization, Vol. 3, North-Holland, Amsterdam.

[10] Salinger, M.: "Vertical Mergers and Market Foreclosure", The Quarterly Journal of Economics, 1988, Vol.103, 345-356. 
[11] Salop, S. and Scheffman, D.: "Raising Rival Costs", The American Economic Review Papers and Proceedings, 1983, Vol.73, 267-271.

[12] Salop, S. and Scheffman, D.: "Cost-Raising Strategies", The Journal of Industrial Economics, 1987, Vol.36, 19-34.

\section{Appendix}

\section{$5.1 \quad$ Appendix 1}

Remind that the profit of each firm under free Cournot is $\pi_{c}=\frac{1}{4} B(S+\Delta S)^{2}$ and the profit of the monopolist under blockaded entry is $\pi_{M}^{S}=B S^{2}$, where $B=b \alpha^{2}$

We can express the blockaded entry profit according to the level of initial stock in the input market. If the stock is $S+\Delta S$, the profit of the monopolist obtains as $\pi_{M}^{S+\Delta S}=B(S+\Delta S)^{2}$, from which we can express $B S \Delta S$ as $\frac{\pi_{M}^{S+\Delta S}-\pi_{M}^{S}-\pi_{M}^{\Delta S}}{2}$.

Returning to the expression of the profit under free Cournot, namely $\frac{1}{4}\left(B S^{2}+2 B S \Delta S+\Delta S^{2}\right)$, we can now replace the term $B S \Delta S$ in this expression to obtain

$$
\pi_{c}=\frac{1}{4} \pi_{M}^{S}+\frac{\pi_{M}^{S+\Delta S}-\pi_{M}^{S}-\pi_{M}^{\Delta S}}{4}+\frac{1}{4} \pi_{M}^{\Delta S} .
$$

Rearranging the terms, we get

$$
\pi_{c}=\frac{1}{4} \pi_{M}^{S+\Delta S}
$$

Hence, given the cost to deter entry $C=p_{M}^{*} \Delta S$, condition (4), if entry is accommodated, writes as

$$
C>\pi_{M}^{S}-\frac{1}{4} \pi_{M}^{S+\Delta S}
$$

\subsection{Appendix 2}

In this appendix, we show that the cooperative solution between the downstream and upstream monopolists gives them a higher total profit then the sum of the profits they obtain when entry is accommodated in the output market. This constitutes a necessary condition for merging. The joint profit 
maximization leads to the use of an amount of input equal to $\frac{a}{2 \alpha \beta}$. Substituting this value in the expression of the joint profit $(a-b \alpha Z) \alpha Z$, we get that the profit under merger obtains as $\frac{a^{2}}{4 b}$.

When entry is accommodated, the profit of the downstream firm, as a Cournot competitor, amounts to $\frac{a^{2}-2 a \alpha b S}{12 b}$, to which we must add the profit obtained by the input seller at equilibrium in the bilateral case, namely $\frac{a^{2}}{6 b}$.Summing these two magnitudes we get the total profit realized by the downstream and upstream monopolist under entry accommodation, namely $\frac{3 a^{2}-2 \alpha a b S}{12 b}$. A direct comparison of joints profits and profits obtained under accommodation shows that merging is always more profitable.

$$
\begin{aligned}
& \frac{\partial}{\partial Z}((a-b \alpha(S+\Delta S)) \alpha Z-p Z)=a \alpha-p-(S+\Delta S) b \alpha^{2} \\
& p=a \alpha-(S+\Delta S) b \alpha^{2} \\
& \left((a-b \alpha(S+\Delta S)) \alpha Z-\left(a \alpha-(2(S+\Delta S)+Z) b \alpha^{2}\right) Z\right)=Z \alpha(a-b \alpha(S+S \Delta))- \\
& Z\left(a \alpha-b \alpha^{2}(2 S+Z+2 S \Delta)\right)=\alpha^{2} b Z(S+S \Delta+Z)
\end{aligned}
$$


Département des Sciences Économiques de l'Université catholique de Louvain

Institut de Recherches Économiques et Sociales

Place Montesquieu, 3

1348 Louvain-la-Neuve, Belgique 